\title{
Human Intestinal Trematodiases in India: An Overview
}

\author{
${ }^{1}$ Abhishek Mewara, ${ }^{2}$ Neha Jain, ${ }^{3}$ Nancy Malla
}

\begin{abstract}
Intestinal trematode infections are of significant public health importance in endemic areas, especially in Southeast Asia. The epidemiological studies are scarce and asymptomatic infections are usually not recorded. In India, the hospitalbased reports, mainly from Bihar, Uttar Pradesh, West Bengal and Assam, reveal that the intestinal trematodes of human pathogenic importance are Fasciolopsis buski, Metagonimus species, and Gastrodiscoides hominis. Fasciolopsiasis due to $F$. buski is the most prevalent infection. The clinical diagnosis is presumptive and is usually confirmed by the examination of faecal samples and/or following endoscopy examination. The diagnostic challenges are low sensitivity of direct microscopy techniques and accurate species identification. Evaluation of multiple samples and application of sensitive techniques may reveal a higher positivity. The complications and extraintestinal manifestations following infection are also underestimated. In endemic areas, high worm load following repeated infections leads to complications, such as intestinal obstruction and perforation. Extraintestinal manifestations may involve spine, brain, kidneys, and the myocardium. If left untreated, the infection may cause significant morbidity and mortality. Praziquantel is the drug of choice and nitazoxanide therapy has also been reported effective for treatment. The reports indicating the implementation and effectiveness of any control strategies are lacking. The formulation and implementation of control strategies need to be based on a holistic approach, keeping in view multiple key factors, such as awareness of the infection and its complications, polyparasitism, population at risk, and zoonotic/aquatic transmission. A well-designed integrated program may simultaneously prevent multiple infections in addition to the intestinal trematode infections.
\end{abstract}

Keywords: Fasciolopsiasis, Gastrodiscoides, Metagonimiasis, Trematodes.

How to cite this article: Mewara A, Jain N, Malla $N$. Human Intestinal Trematodiases in India: An Overview. J Gastrointest Infect 2018;8(1):39-45.

Source of support: Nil

Conflict of interest: None

${ }^{1}$ Assistant Professor, ${ }^{2}$ Senior Resident, ${ }^{3}$ Former Professor and Head

${ }^{1-3}$ Department of Medical Parasitology, Postgraduate Institute of Medical Education and Research, Chandigarh, India

Corresponding Author: Nancy Malla, Former Professor and Head, Department of Medical Parasitology, Postgraduate Institute of Medical Education and Research, Chandigarh, India e-mail: drmallanancy@gmail.com

\section{INTRODUCTION}

An estimated 40-50 million individuals are infected with one or more intestinal trematodes worldwide, although the exact numbers of people at risk are not known..$^{1-3}$ The infections have been mainly reported from China, Korea, Thailand, Bangladesh, Myanmar, Malaysia, Sumatra, Laos, Vietnam, India, and recently from Bolivia and Central and South America. ${ }^{4}$ Approximately 70 trematode species are known to colonize the human intestine, while only a few species cause disease. The species of intestinal flukes of public health importance are mainly Fasciolopsis buski, Metagonimus yokogawai, Gastrodiscoides hominis, Echinostoma species, Gymnophalloides seoi, Haplorchis species and Heterophyes species. ${ }^{5}$ Trematodes parasitizing the human intestinal tract are flat hermaphroditic worms that vary in length from a few millimeters to several centimeters. The detailed review of the reports in Southeast Asia provides details of the various aspects of trematodiases including infecting species, epidemiology, pathogenicity, diagnostic applications and treatment. ${ }^{2}$ Further, the geographical boundaries of these seemingly restricted infections are now expanding through migrants and travelers. ${ }^{5}$ However, despite the public health impact and emerging infections, these diseases are of low priority for research funding. ${ }^{6}$

The trematode infections are endemic in many areas in India and F. buski, M. yokogawai, and G. hominis are the primary species of human pathogenic importance in the country. Although there are limited reports of human infections, it is estimated that most infections are asymptomatic and thus underreported. In symptomatic subjects, the worms may cause mild ailment including abdominal pain, diarrhea, nausea, vomiting and anorexia, while in patients with heavy worm load, complications and extraintestinal manifestations may lead to morbidity and mortality if not diagnosed and treated timely. This review focuses on the intestinal trematodes of pathogenic importance to humans reported from India and highlights the need for timely diagnosis followed by treatment along with awareness of the infection and its complications in the endemic population for the ultimate control of these infections.

\section{Fasciolopsiasis}

Fasciolopsiasis is caused by F. buski, the giant intestinal fluke, measuring $2-7.5 \mathrm{~cm}$ in length and $8-20 \mathrm{~mm}$ in breadth. The adult worms are found in the small intestine of pigs and man, the definitive hosts. The previous prevalence 
studies have mostly been reported in school children and the prevalence rate varies in different countries, viz., $10 \%$ in Thailand, ${ }^{7}$ 25\% in Taiwan, ${ }^{8} 36 \%$ in Bangladesh, ${ }^{9}$ and $57 \%$ in China. ${ }^{10}$ In India, the hospital-based studies have been mainly reported from Bihar, Uttar Pradesh, West Bengal and Assam. ${ }^{4}$ The prevalence rates of $60 \%$ in Assam, ${ }^{11} 63 \%$ in Palghar Taluk of Maharashtra, ${ }^{12} 29 \%$ in Mumbai, ${ }^{13}$ and $22.4 \%$ in Uttar Pradesh ${ }^{14}$ may be underestimates as most of the infections are asymptomatic. Sporadic cases have also been reported from Manipur and Odisha. ${ }^{15,16}$ Heavy infections lead to various symptoms and signs, including abdominal pain, diarrhea, vomiting, leukocytosis, and eosinophilia, while severe cases may develop intestinal erosions, hemorrhage and ulcers.

The epidemiological studies in livestock indicate that the infections are highly prevalent in animals. The primary reservoirs of this parasite are swine in whom a high endemicity of infection is maintained mainly by improper drainage of sewage in farms. In the Northeastern state of Meghalaya, 53\% cattle and $12.9 \%$ pigs were found to harbor the parasite. ${ }^{17}$ The fluke has been reported in the pig populations from different parts of the country, including Bihar (55.5\%), Assam (33\%), Uttar Pradesh (29.4\%) and Tamil Nadu (12.5\%). ${ }^{14,18-20}$ The intermediate hosts are freshwater snails of the genera Segmentina, Hippeutis and Gyraulus. ${ }^{2}$ Humans usually acquire infection by ingesting the metacercariae adhering to the shell, stem, or roots of aquatic plants, such as water chestnuts (Trapa natans), water caltrops, water bamboo, water lily and lotus which propagate in seasonal ponds and storage tanks in rural areas where the water is frequently contaminated with feces from infected pigs. ${ }^{21}$ Humans are mainly infected by ingestion of encysted cercariae of the parasite through consumption of unprocessed or poorly cooked aquatic plants, peeling off the skin of the raw nuts by mouth, ${ }^{2}$ or using blow pipes made up of stems of lily and lotus while playing. ${ }^{16}$

Although epidemiological studies are scarce, there are several case reports from different geographical areas in India. A 35-year-old female patient from Azamgarh, Uttar Pradesh in North India with complaints of abdominal pain, diarrhea, anorexia and abdominal distension after meals was diagnosed with fasciolopsiasis and responded to praziquantel therapy. Another 6-year-old child from the same area complaining of abdominal pain, nausea and vomiting was given albendazole therapy and vomited a worm following treatment which was identified as F. buski. Further investigation indicated that water chestnuts were cultivated in the area of residence. ${ }^{22}$ The report suggests the need to identify the snail vectors and to adopt control measures. From northern Bihar, a patient with the complaints of diarrhea, vomiting, generalized pain abdomen and loss of weight was diagnosed of fasciolopsiasis by stool examination and endoscopy. However, the patient succumbed to the illness, despite praziquantel therapy, indicating significant mortality following infection. The epidemiological history revealed ingestion of raw water caltrops and water chestnuts. An awareness of the infection and knowledge of mode of transmission in the people residing in endemic regions is desired. ${ }^{23}$ Another report from Muzzaffarpur, Bihar with similar complaints was diagnosed with heavy worm load of $F$. buski resulting in mortality after 3 days despite treatment with praziquantel. ${ }^{24}$ F. buski has also been observed in an ileostomy opening during exploratory laparotomy performed to manage blunt trauma abdomen. ${ }^{25}$ Another case of a boy vomiting four live adult worms identified as F. buski has been reported from a previously non endemic area of Odisha. ${ }^{26}$ Recently, diagnosis of fasciolopsiasis in three subjects led to the identification of a new focus of infection in the Phulwaria village in East Champaran, Bihar, wherein faecal sampling in the community revealed F. buski in 55 out of 57 samples, indicating significant burden of infection in the area. ${ }^{27}$ Another more recent hospital-based study from Bihar revealed analysis of the clinical, sociodemographic characters and outcomes of 56 children in 2 to 14 years age group diagnosed of fasciolopsiasis, and found that diarrhoea was the most common symptom $(85.7 \%)$ and anemia was the most common sign $(71.4 \%)$ in patients. Protein energy malnutrition, tuberculosis and co-parasitism were the other significant findings, and nonavailability of safe drinking water supply to majority of subjects and open defaecation were other compounding factors. ${ }^{28}$

The complication of high worm load (25 worms) infection leading to intestinal perforation in a child residing in Barabanki district of Uttar Pradesh, India indicates that preventive measures and health education in the endemic areas is lacking. ${ }^{29}$ Unusually heavy infection with F. buski with dozens of worms weighing around $1 \mathrm{~kg}$ has been reported from New Delhi in a patient from eastern Uttar Pradesh and it has been emphasized that this trematode is by no means a rarity in that region. ${ }^{30}$ Similarly, there are other reports of small bowel stricture and perforation, ${ }^{31}$ mechanical obstruction leading to appendicitis, ${ }^{32}$ and parasite infestation leading to acute kidney failure, ${ }^{33}$ suggesting significant morbidity and mortality rates following infection, if not diagnosed and treated early.

\section{Metagonimiasis}

Metagonimiasis caused due to $M$. yokogawai is a public health problem in Japan, Korea, China, Russia, Spain and Indonesia. The infection is transmitted by eating pickled, 
raw or undercooked fresh water fish containing the metacercariae. The symptomatic subjects usually complain of anorexia, weakness, abdominal pain, dyspepsia, nausea, vomiting and diarrhea with mucus-rich feces. In India, the first human cases were reported from Assam, wherein eggs morphologically similar to those of the members of the family Heterophyidae were found in stool samples. ${ }^{34}$ In another report from New Delhi, in a child with complaints of diarrhea, characteristic eggs of M. yokogawai were observed in the faecal sample. ${ }^{35}$ The reports indicate presence of infection foci in India and a need to adopt preventive measures. Further, embolization of eggs leading to extraintestinal manifestations involving myocardium, brain and spinal cord indicate significant potential of morbidity and mortality following infection. ${ }^{36}$

\section{Gastrodiscoides Hominis Infection}

The parasite $G$. hominis has pig as the common reservoir. It resides in the large intestine of the pig and measures 8 to $14 \mathrm{~mm}$ in length and 4 to $5 \mathrm{~mm}$ in breadth. Human infection occurs by consumption of contaminated vegetation (water caltrops and chestnuts) and infected fish leading to abdominal pain, colic, and mucoid diarrhea. Having first been described from India, ${ }^{37}$ the reports of human infection of this fluke from India are scarce. It has been mainly reported in Assam, Bihar, Orissa and Bengal as the infection is mostly asymptomatic and thus prone to underreporting. ${ }^{38}$ In a postnecropsy study in cattle and pigs, infection due to G. hominis and other trematodes, such as Fasciola gigantica, Eurytrema pancreaticum, Opisthorchis noverca, Artyfechinostomum malayanum and F. buski were found in abundance in subtropical Northeast hilly region of India. ${ }^{17}$ In another study from Bareilly in Uttar Pradesh, 27\% of the total 233 slaughter pigs were found to be infected with $G$. hominis and half of them had coinfection with F. buski. ${ }^{39}$ In different localities of Assam, G. hominis was reported in $41.2 \%$ and F. buski in $59.7 \%$ of the total 221 faecal specimens. ${ }^{11} \mathrm{G}$. hominis along with other intestinal parasites has been diagnosed in a 20-year-old patient from Bihar with main complaint of bilateral pitting pedal edema and the patient responded to specific treatment. ${ }^{40} \mathrm{G}$. hominis was also visualized in colon by endoscopy in a patient from Mumbai. ${ }^{41}$ Another report from Varanasi, Uttar Pradesh, of a young adult male who presented with complaints of passing frequent formed stools and excessive mucus, initially labeled as a case of irritable bowel syndrome and following inadequate relief with empirical therapy, was later identified as G. hominis infection. However, the patient did not respond completely to praziquantel therapy also, so the authors postulated that presence of the parasite may be of commensal nature. ${ }^{42}$

\section{Intestinal Trematode Infection and HIV}

Intestinal helminths induce immunological alterations that favor the progression from human immunodeficiency virus (HIV) seroconversion to acquired immunodeficiency syndrome. Further, the natural course of parasitic infections may be altered in an HIV infected person, thus leading to fulminant infection. An HIV infected patient from a rural coastal area in Manipal, Karnataka, with complaints of diarrhea and bleeding per rectum was diagnosed of multiple infections including that of F. buski. ${ }^{43}$

\section{Intestinal Trematodes and Coinfection}

The coinfection with multiple pathogens has an impact on the severity of disease and strategies for the joint control of such infections. Polyparasitism is widely reported from different geographical areas in India and its impact on human health has been underestimated. The multiple intestinal parasite infections indicate the poor hygiene, untreated sewage and lack of knowledge in the population residing in endemic areas. Polyparasitism was reported in 14 (25\%) out of 56 F. buski infected children in Bihar, the most commonly associated parasite being Hymenolepis nana followed by Ascaris lumbricoides. ${ }^{28}$ The coinfection of F. buski along with Strongyloides stercoralis, A. lumbricoides, Trichuris trichiura and Ancylostoma duodenale has been reported from New Delhi in a 7-year-old migrant boy from Bihar. ${ }^{44}$ Another child from North India was coinfected with F. buski, A. lumbricoides and hookworm. ${ }^{45}$ Adults are also reported to harbor multiple parasites. A 41-year-old HIV positive patient with complaints of bleeding per rectum was found to be infected with multiple pathogens including F. buski, Taenia sp. and Aspergillus sp. ${ }^{43}$ Similarly, a 20 -year-old female patient from Bihar presented with bilateral progressive pitting pedal edema, mild abdominal discomfort and nausea. Endoscopy, colonoscopy and stool examination revealed multiple pathogens including the trematodes (F. buski and G. hominis) and protozoa (Entamoeba and Giardia sp.). The family members of this patient were not found to harbor the intestinal parasites. ${ }^{40}$

\section{Intestinal Trematode Infections and Allergy}

In chronic infections, especially in endemic areas, the parasites may survive for very long periods in the human body and may associate with tightly regulated Th-2 type of immunological response. The individuals exposed to trematode infection may have allergic inflammatory response to the parasite or its antigen but anaphylactic reactions are very rare. A case of anaphylaxis has been reported in a woman from Spain after eating raw fish infected with $H$. heterophyes. ${ }^{46}$ 


\section{Rare Trematode Infections}

Many flukes of the families Echinostomatidae and Heterophyidae have been reported from India. Echinostomatidae are predominantly found in birds and can occasionally parasitize fishes and reptiles. A recent study from Odisha found $1.9 \%$ of Banjara fowls infected with Echinostoma revolutum. ${ }^{47}$

\section{Artyfechinostomum Genus}

Artyfechinostomum malayanum, previously known as Echinostoma malayanum, was first described from human cases in Malaysia and has also been reported from Kolkata in India. ${ }^{48}$ Human infestation of Artyfechinostomum mehrai (later Artyfechinostomum malayanum) has been reported in a girl suffering from diarrhea, vomiting and loss of weight, ${ }^{49,50}$ and also observed in association with bowel perforation in a patient. ${ }^{51}$ Artyfechinostomum sufrartyfex, a related species, has been reported from humans in Assam and Tamil Nadu, 52,53 and also from pigs in Uttar Pradesh, ${ }^{54}$ and cats and dogs from West Bengal. ${ }^{55,56}$ Another species, Artyfechinostomum oraoni has been found to infect a tribal community in West Bengal. ${ }^{57}$ The species was associated with human cases of diarrhea in this community, and to understand the nature of the associated illness, two naturally infected pigs of this locality were captured and followed up. Both the pigs developed fatal diarrhea in 5 months with a hemorrhagic and edematous jejunum and duodenum. ${ }^{58} \mathrm{~A}$ case of Echinostoma ilocanum infection has been reported from Bihar, where the trematode was recovered from the vomitus of a patient having history of consumption of roasted fish and snails. ${ }^{59}$

\section{Procerovum varium (Family Heterophyidae)}

P. varium was found to cause ocular infection in children who bathed in ponds or rivers of South India and was diagnosed by molecular techniques. The molecular analysis of surgically obtained ocular granuloma tissue and trematode cercariae released by the snail species Melanoides tuberculata showed maximum sequence similarity with $P$. varium (family Heterophyidae), thus suggesting water as the source of infection and snails as the vectors. ${ }^{60}$

All these reports suggest that these flukes are much more prevalent in the Indian subcontinent than realized.

\section{Diagnosis}

The clinical diagnosis is presumptive due to vague symptoms mimicking several intestinal pathologies. The diagnosis in a highly suspected patient is usually confirmed by observing the characteristic eggs and/or adult worms in faecal samples and / or vomitus; however, the low sensitivity of direct stool examination may pose problem in patients with low worm load. The sensitivity can be improved by examination of multiple samples and use of concentration techniques. The species identification of heterophyid eggs based on faecal examination is challenging because of the close resemblance of eggs of different heterophyid species; however, the size and morphology of the ova in conjunction with endemicity in the index area may provide some clue to the diagnosis. The diagnosis may be confirmed after recovering the adult parasite after treatment and purgation. ${ }^{61}$ Specific antibody detection may also help the diagnosis. ${ }^{62}$ The application of molecular techniques has helped in the species identification, yet till date, these are restricted to research settings.

\section{Molecular Studies}

Molecular studies conducted on F. buski have utilized the $18 \mathrm{~S}$ ribosomal ribonucleic acid gene sequences for identification. ${ }^{63}$ Using the same, fluke specimens emitted in the vomitus of a child with abdominal pain were confirmed as F. buski. ${ }^{64}$ Species-specific internal transcribed spacer (ITS) region sequences of ribosomal deoxyribonucleic acid (rDNA) have also been described from parasites collected from swine in Assam and it has been found that the sequences of eggs and adults were identical in length and composition, thus indicating that these sequences are conserved in different parasite stages and can be used as species markers. ${ }^{65}$ The ITS2-specific primers have also been designed and used to study the secondary structure homologies and phylogenetic relationships, and can also be utilized for epidemiological investigations of trematodiasis. ${ }^{66}$ The mitochondrial genome of F. buski has been used to design specific polymerase chain reaction (PCR) primers for identification and also to aid the taxonomy, comparative mitochondrial genomics and systematic studies on these trematodes. ${ }^{67}$ The molecular characterization of $G$. hominis was done from Northeast region of India using PCR amplifications of rDNA ITS (1 and 2) sequences and revealed close similarity between members of the family Paramphistomidae. ${ }^{68}$ From states of Tamil Nadu and Kerala in South India, real-time and conventional PCR assays targeting rDNA regions spanning the ITS2 and $28 \mathrm{~S}$ sequences have been used for the identification of the trematode P. varium. ${ }^{60}$ Recently, a Northeast India Helminth Parasite Information Database (NEIHPID) has been created which is expected to provide data on the host, geographical distribution, diagnostic characters and image data of various helminths endemic in Northeast India. ${ }^{69}$ 


\section{Treatment}

Praziquantel is the drug of choice for infections with trematodes. The single oral dose of 10 to $20 \mathrm{mg} / \mathrm{kg}$ is usually effective. Nitazoxanide has also been found effective for fasciolopsiasis. ${ }^{26}$ An experimental study in mice showed that artesunate was 100\% effective in reducing the intestinal heterophyides, suggesting it to be a plausible therapy for treatment of human heterophyidiasis. ${ }^{70}$

\section{Prevention and Control}

The role of pigs is important in the maintenance and propagation of most food-borne parasitic zoonoses in India. Although proper cooking of meat, fish and vegetables is generally practiced throughout India by virtue of traditional social and culinary practices, yet, unhygienic living conditions, open defaecation, lack of infrastructure, poverty and lack of education are the major factors in the transmission of food-borne pathogens. ${ }^{71}$ Boiling of water chestnuts and other aquatic plants before consumption ensures destruction of metacercariae. Molluscicidal agents can be used for control of snails to reduce transmission in the ponds. The recent identification of a major endemic focus of $F$. buski in East Champaran district in Bihar emphasizes the gaps in our understanding of the epidemiology of trematodiases in India and suggest the need to identify more infected foci to be able to adopt specific preventive and control measures in endemic areas to prevent morbidity and mortality from these neglected diseases. $^{72}$

\section{CONCLUSION}

In conclusion, intestinal trematode infections seem to be underreported from the Indian subcontinent. In India, the studies and case reports are mainly from the states of Bihar, Uttar Pradesh, West Bengal and Assam. However, due to frequent travel and migration in this jet age, the boundaries of infection may not remain restricted. The epidemiological reports are scarce and the infections are presumed to remain asymptomatic and restricted to the gastrointestinal tract; however, hospital-based studies reveal that in endemic areas, high worm load following repeated infections can lead to complications, such as intestinal obstruction and perforation, and patients may have extraintestinal manifestations involving spine, brain, kidneys and the myocardium, resulting in substantial morbidity and mortality, if not diagnosed and treated timely. The diagnosis is mainly based on examination of faecal samples and / or following endoscopy examination. The main diagnostic challenges are the parasite species identification and low sensitivity of direct microscopy techniques. More studies evaluating the sensitivity of the diagnostic techniques, especially molecular assays, are desired. Although the infection is preventable, yet lack of awareness regarding mode of the parasite transmission and complications following repeated infections in endemic population appear to be the main lacunae for prevention of this infection. Comprehensive control strategies need to be framed based on key factors, such as imparting knowledge of infection in the population at risk, polyparasitism and zoonotic/aquatic transmission, for the ultimate prevention of human intestinal trematodiasis.

\section{REFERENCES}

1. Fried B, Graczyk TK, Tamang L. Food-borne intestinal trematodiases in humans. Parasitol Res 2004 Jun;93(2):159-170.

2. Chai JY, Shin EH, Lee SH, Rim HJ. Foodborne intestinal flukes in Southeast Asia. Korean J Parasitol 2009 Oct;47 (Suppl): S69-S102.

3. Keiser J, Utzinger J. Food-borne trematodiases. Clin Microbiol Rev 2009 Jul;22(3):466-483.

4. Khurana, S.; Malla, N. Water and food borne trematodiasis in humans. In: Singh PP, Sharma V, editors. Water and health. New Delhi: Springer; 2014. pp. 219-227.

5. Fürst T, Sayasone S, Odermatt P, Keiser J, Utzinger J. Manifestation, diagnosis and management of foodborne trematodiasis. BMJ 2012 Jun;344:e4093.

6. Toledo R, Esteban JG, Fried B. Current status of food-borne trematode infections. Eur J Clin Microbiol Infect Dis 2012 Aug;31(8):1705-1718.

7. Bunnag D, Radomyos P, Harinasuta C. Field trial on the treatment of fasciolopsiasis with praziqauntel. Southeast Asian J Trop Med Public Health 1983 Jun;14(2):216-219.

8. Shyu LY, Lee HH, Chen ER. A preliminary study on epidemiology of fasciolopsiasis in Tainan Hsien, south Taiwan. Chinese J Microbiol Immunol 1984 May;17(2):118-120.

9. Rahman KM, Idris M, Azad Khan AK. A study on fasciolopsiasis in Bangladesh. J Trop Med Hyg 1981 Apr;84(2):81-86.

10. Lee HH. Survey of Fasciolopsis buski infection among children of Liu-ying primary school in Tainan country. Chinese J Microbiol Immunol 1972 Dec;5(3):110-114.

11. Buckley JJ. Observations on Gastrodiscoides hominis and Fasciolopsis buski in Assam. J Helminthology 1939 Jan;17(1):1-12.

12. Manjarumkar PV, Shah PM. Epidemiological study of Fasciolopsis buski in Palghar Taluk. Indian J Public Health 1972 Jan;16(1):3-6.

13. Shah A, Gadqil RK, Manohar KD. Fasciolopsiasis in Bombay: a preliminary communication. Indian J Med Sci 1966 Nov;20(11):805-811.

14. Chandra SS. Epidemiology of Fasciolopsis buski in Uttar Pradesh. Indian J Med Res 1984 Jan;79:55-59.

15. Shantikumar Singh T, Sulochana Devi K, Ibotomba Singh Y. Fasciolopsiasis-a case report from Manipur. Indian J Med Microbiol 1993 Jan-Mar;11(1):56-57.

16. Das MM, Ghosh SK, Satpathy DR, Dash D, Prabaraj KC. Fasciolopsiasis in children of South Orissa. Report of four cases. Ind Med Gaz 1987 Apr;121(4):153-155.

17. Roy B, Tandon V. Seasonal prevalence of some zoonotic trematode infection in cattle and pigs in the North East Zone in India. Vet Parasitol 1992 Feb;41(1-2):69-76. 
18. Sadarao Bharat L, Sinha SR, Sinha S, Kumari S, Mandal KG. Prevalence of Fasciolopsis buski in deshi pigs of Patna. J Vet Parasitol 2011 Dec;25(1):92-93.

19. Sarma BN, Gogoi AR. Studies on helminths and histopathology of some common trematodes of local pigs in Assam. Indian Vet J 1986;63:366-370.

20. Gomathi M, Subramanian N, Muthu M. Prevalence of gastrointestinal parasites in domestic pigs collected from Cheyyar taluk, Thiruvannamalai district. Int J Dev Res 2016 Nov;6(11):10466-10473.

21. Bhatia, BB. Food-borne helminthozoonoses. In: Sood ML, editor. Helminthology in India. Dehradun: Intl Book Dist.; 2003. pp. 1-24.

22. Bhatti HS, Malla N, Mahajan RC, Sehgal R. Fasciolopsiasis-a re-emerging infection in Azamgarh (Uttar Pradesh). Indian J Pathol Microbiol 2000 Jan;43(1):73-76.

23. Kumari N, Kumar M, Rai A, Acharya A. Intestinal trematode infection in North Bihar. J Nepal Med Assoc 2006 JanMar;45(161):204-206.

24. Gupta A, Xess A, Sharma HP, Dayal VM, Prasad KM, Shahi SK. Fasciolopsis buski (giant intestinal fluke)—a case report. Indian J Pathol Microbiol 1999 Jul;42(3):359-360.

25. Mahajan RK, Duggal S, Kumar Biswas N, Duggal N, Hans C. A finding of live Fasciolopsis buski in an ileostomy opening. J Infect Dev Ctries 2010 Jun;4(6):401-403.

26. Mohanty I, Narasimham M V, Sahu S, Panda P, Parida B. Live Fasciolopsis buski vomited out by a boy. Ann Trop Med Public Health 2012 Oct;5(4):403-405.

27. Achra A, Prakash P, Shankar R. Fasciolopsiasis: Endemic focus of a neglected parasitic disease in Bihar. Indian J Med Microbiol 2015 Jul-Sep;33(3):364-368.

28. Saurabh K, Ranjan S. Fasciolopsiasis in children: clinical, sociodemographic profile and outcome. Indian J Med Microbiol 2017 Oct-Dec;35(4):551-554.

29. Bhattacharjee HK, Yadav D, Bagga D. Fasciolopsiasis presenting as intestinal perforation: a case report. Trop Gastroenterol 2009 Jan-Mar;30(1):40-41.

30. Muralidhar S, Srivastava L, Aggarwal P, Jain N, Sharma DK. Fasciolopsiasis-a persisting problem in eastern U.P.-a case report. Indian J Pathol Microbiol 2000 Jan;43(1):69-71.

31. Singh UC, Kumar A, Srivastava A, Patel B, Shukla VK, Gupta SK. Small bowel stricture and perforation: an unusual presentation of Fasciolopsis buski. Case Rep Trop Gastroenterol 2011 Oct-Dec;32(4):320-322.

32. Cao YH, Ma YM, Qiu F, Zhang XQ. Rare cause of appendicitis: Mechanical obstruction due to Fasciolopsis buski infestation. World J Gastroenterol 2015 Mar;21(10):3146-3149.

33. Karthikeyan G, Ramkumar V, Kumar SP, Ramkumar S, Selvamani S, Vetriveeran B, Karuppasamy N, Moses IC. Intestinal infestation with Fasciolopsis buski leading to acute kidney injury. J Assoc Physicians India 2013 Dec;61(12): 936-938.

34. Mahanta J, Narain K, Srivastava VK. Heterophyid eggs in human stool samples in Assam: First report from India. Indian J Commun Dis 1995 Sep;27(3):142-145.

35. Uppal B, Wadhwa V. Rare case of Metagonimus yokogawai. Indian J Med Microbiol 2005 Jan;23(1):61-62.

36. Chai JY, Lee SH. Intestinal trematodes of humans in Korea: metagonimus, heterophyids and echinostomes. Kisaengehunghak Chapchi 1990 Dec;28(Suppl):103-122.

37. Beaver, PC.; Jung, RC.; Cupp, EW. Clinical parasitology. 9th ed. Philadelphia (PA): Lea \& Febiger; 1984.
38. Murty CV, Reddy CR. A case report of Gastrodiscoides hominis infestation. Indian J Pathol Microbiol 1980 Oct;23(4): 303-B-304-B.

39. Dutt SC, Srivastava HD. The life history of Gastrodiscoides hominis (Lewis and McConnel, 1876) Leiper, 1913, the amphistome parasite of man and pig. J Helminthol 1972;46(1):35-46.

40. Sunil HS, Gandhi BP, Avinash B, Devi G, Sudhir U. Parasitic zoo of Fasciolopsis buski, Gastrodiscoides hominis, Giardiasis intestinalis, and Entamoeba histolytica. J Indian Acad Clin Med 2014 Jan;15(3):240-242.

41. Gupte A, Shah C, Koticha A, Shukla A, Kuyare S, Bhatia S. Gastrodiscoides hominis infestation of colon: endoscopic appearance. Gastrointest Endosc 2014 Apr;79(4):549-550.

42. Shukla SK, Asati PK, Banerjee T, Dixit VK. Rare trematode infestation in irritable bowel syndrome: Pathogen or commensal? J Dig Endosc 2016 Jan;7(3):123-124.

43. Ballal M, Martena S. An unusual presentation of diarrhea by Fasciolopsis buski, Taenia spp. and Aspergillus spp. in a retro positive patient. A first case report from rural coastal India-Manipal, Karnataka. Ann Trop Med Public Health 2012 Dec;5(5):543-545.

44. Rai S, Wadhwa V, Kharbanda P, Uppal B. A case of polyparasitism involving a trematode and four different nematodes in a migrant from Bihar. Indian J Med Microbiol 2007 Jan;25(1):62-63.

45. Bhattacharya S, Khurana S, Bhatti HS, Singhi S, Malla N. Polyparasitism: Fasciolopsis buski, Ascaris lumbricoides and Hookworm coinfection in a child. Trop Gastroenterol 2010 Apr-Jun;31(2):126-127.

46. Martínez JC, Armentia A, Vega JM, Callejo A, Gómez A. Anaphylactic reaction concurrent with Heterophyes heterophyes infestation. Rev Esp Alergol Inmunol Clín 1999 Feb;14(1): 37-39.

47. Hembram A, Panda MR, Mohanty BN, Pradhan CR, Dehuri M, Sahu A, Behera M Prevalence of gastrointestinal helminths in Banaraja fowls reared in semi-intensive system of management in Mayurbhanj district of Odisha. Vet World 2015 Jun;8(6): 723-726.

48. Maji AK, Bera DK, Manna B, Nandy A, Addy M, Bandyopadhyay AK. First record of human infection with Echinostoma malayanum in India. Trans R Soc Trop Med Hyg 1993 NovDec;87(6):673.

49. Raghunathan VS, Srinivasan T. Artyfechinostomum mehrai infestation. A case report. J Indian Med Assoc 1962 May;38:485-487.

50. Reddy DB, Ranganaykamma I, Venkataratnam D. Artyfechinostomum mehrai infestation in man. J Trop Med Hyg 1964 Mar;67:58-59.

51. Kaul BK, Singhal GD, Pillai PN. Artyfechinostomum mehrai infestation with bowel perforation. J Indian Med Assoc 1974 Oct;63(8):263-265.

52. Lane C. Artyfechinostomum surfrartyfex. A new parasitic echinostome of man. Indian J Med Res 1915;2(4):977-983.

53. Reddy DG, Varmah K. Paryphostomum sufrartyfex (intestinal fluke) infection in man. Ind Med Gaz 1950 Dec;85(12):546-547.

54. Ahluwalia SS. Studies on some helminths of the domestic pig (Sus scrofa domestica) in western Uttar Pradesh. J Helminthol 1962 Dec;36(4):347-364.

55. Bandyopadhyay AK, Nandy A. A preliminary observation on the prevalence of echinostomes in a tribal community near Calcutta. Ann Trop Med Parasitol 1986 Jun;80(3):373-375.

56. Dubey JP, Srivastava HO, Sahasrabudhe VK. Artyfechinostomum sufrartyfex infection in cat and dog in India. Trop Geogr Med 1969 Jun;21(2):210-213. 
57. Bandyopadhyay AK, Manna B, Nandy A. Human infection of Artyfechinostomum oraoni n. sp. (Paryphostominae: Echinostomatidae) in a tribal community, "Oraons" in West Bengal, India. Indian J Parasitol 1989;13:191-196.

58. Bandyopadhyay AK, Maji AK, Manna B, Bera DK, Addy M, Nandy A. Pathogenicity of Artyfechinostomum oraoni in naturally infected pigs. Trop Med Parasitol 1995 Jun;46(2):138-139.

59. Grover M, Dutta R, Kumar R, Aneja S, Mehta G. Echinostoma ilocanum Infection. Indian Pediatr 1998 Jun;35(6):549-552.

60. Arya LK, Rathinam SR, Lalitha P, Kim UR, Ghatani S, Tandon V. Trematode fluke Procerovum varium as cause of ocular inflammation in children, South India. Emerg Infect Dis 2016 Feb;22(2):192-200.

61. Chai, JY. Echinotomes in humans. In: Fried B, Toledo R, editors. The biology of echinostomes. New York (NY): Springer; 2009. pp. 147-183.

62. Quang TD, Duong TH, Richard-Lenoble D, Odermatt P, Khammanivong K. Emergence in humans of fascioliasis (from Fasciola gigantica) and intestinal distomatosis (from Fasciolopsis buski) in Laos. Sante 2008 Jul-Sep;18(3):119-124.

63. Mas-Coma S, Bargues MD, Valero MA. Fascioliasis and other plant-borne trematode zoonoses. Int J Parasitol 2005 Oct; 35(11-12):1255-1278.

64. Le TH, Nguyen VD, Phan BU, Blair D, McManus DP. Case report: unusual presentation of Fasciolopsis buski in a Vietnamese child. Trans R Soc Trop Med Hyg 2004 Mar;98(3):193-194.

65. Prasad PK, Tandon V, Chatterjee A, Bandyopadhyay S. PCRbased determination of internal transcribed spacer (ITS) regions of ribosomal DNA of giant intestinal fluke, Fasciolopsis buski (Lankester, 1857) Looss, 1899. Parasitol Res 2007 Nov; 101(6):1581-1587.

66. Prasad PK, Goswami LM, Tandon V, Chatterjee A. PCR-based molecular characterization and in silico analysis of food-borne trematode parasites Paragonimus westermani, Fasciolopsis buski and Fasciola gigantica from Northeast India using ITS2 rDNA. Bioinformation 2011 Mar;6(2):64-68.

67. Biswal DK, Ghatani S, Shylla JA, Sahu R, Mullapudi N, Bhattacharya A, Tandon V. An integrated pipeline for next generation sequencing and annotation of the complete mitochondrial genome of the giant intestinal fluke, Fasciolopsis buski (Lankester, 1857) Looss, 1899. PeerJ 2013 Nov;1:e207.

68. Goswami LM, Prasad PK, Tandon V, Chatterjee A. Molecular characterization of Gastrodiscoides hominis (Platyhelminthes: Trematoda: Digenea) inferred from ITS rDNA sequence analysis. Parasitol Res 2009 Jun;104(6):1485-1490.

69. Biswal DK, Debnath M, Kharumnuid G, Thongnibah W, Tandon V. Northeast India Helminth Parasite Information Database (NEIHPID): knowledge base for Helminth parasites. PLoS One 2016 Jun;11(6):e0157459.

70. Fathy FM. Anthelmintic effect of artesunate in experimental heterophyid infection. J Egypt Soc Parasitol 2011 Aug;41(2):469-483.

71. Bhatia BB. Current status of food-borne parasitic zoonoses in India. The Southeast Asian. J Trop Med Public Health 1992 Jan;22(Suppl):36-41.

72. Khurana S. Fasciolopsiasis: endemic focus of a neglected parasitic disease in Bihar Indian. J Med Microbiol 2016 AprJun;34(2):247. 